\title{
Microwave-assisted one-pot multicomponent synthesis of indole derived fluorometric probe for detection of $\mathrm{Co}^{2+}$ ions
}

\author{
Rizana Azees $^{1}$, Asitha T. Cooray ${ }^{1}$, K.G.U.R. Kumarasinghe ${ }^{1 *}$ \\ ${ }^{1}$ Department of Chemistry, Faculty of Applied Sciences, University of Sri Jayewardenepura, Sri Lanka
}

Date Received: 28-11-2021 Date Accepted: 17-12-2021

\begin{abstract}
Cobalt $\left(\mathrm{Co}^{2+}\right)$ is an essential constituent in the human body while excessive exposure leads to severe systemic toxic reactions which highlight the importance of developing effective methods to detect $\mathrm{Co}^{2+}$ ions. A simple and highly efficient fluorescence enhanced turn OFF-ON chemosensor was synthesized to detect the paramagnetic $\mathrm{Co}^{2+}$. The ligand, $N$-((1H-indol-3-yl)(phenyl)methyl)aniline (L), was synthesized in $92 \%$ yield by means of hydrated ferric chloride catalyzed one -pot multicomponent microwave irradiation in the presence of Indole, benzaldehyde, and aniline as reactants. The major green principles of waste prevention, high atom economy (94.3\%), green solvent, higher energy efficiency, and catalysis were the highlights of the ligand synthesis. The ligand exhibited remarkable fluorescence enhancement with $\mathrm{Co}^{2+}$ and a turn $\mathrm{ON}$ ratio of over 160 -fold in $\mathrm{MeOH} / \mathrm{H}_{2} \mathrm{O}$ (at $\mathrm{pH} 3.5$ ) solution at an excitation wavelength of $369 \mathrm{~nm}$ in the Ultra-Violet range. The detection limit of $\mathbf{L}-\mathrm{Co}^{2+}$ was $2.2 \mu \mathrm{M}$. The excitation and the emission spectra indicated stoke's shift of $93 \mathrm{~nm}$ which supports the fluorescence enhancement observed in $\mathrm{L}-\mathrm{Co}^{2+}$ with respect to the free ligand. The Job's plot indicated fluorometric sensing of $\mathrm{Co}^{2+}$ ascribed to the complex formation with a stoichiometric ratio of $2: 1\left(\mathrm{~L}^{-} \mathrm{Co}^{2+}\right)$. Furthermore, the high linearity $\left(r^{2}=0.992\right)$ observed in the Benesi Hildebrand plot in a wide concentration range of $0.5-80 \mu \mathrm{M}$ confirmed the above stoichiometric ratio. The association constant (Ka) for the $\mathbf{L}$ $\mathrm{Co}^{2+}$ was determined to be $8.382 \times 10^{4} \mathrm{M}^{-1} \pm 5.8 \times 10^{3} \mathrm{M}^{-1}$. The prepared $\mathrm{Co}^{2+}$ fluorometric probe indicated long-term stability in $-18{ }^{\circ} \mathrm{C}$ up to 45 days. Furthermore, the presence of $\mathrm{Fe}^{2+}$ and $\mathrm{Fe}^{3+}$ in the medium with $\mathrm{Co}^{2+}$ exhibited an interference effect in the fluorescence intensities. Upon further concentration studies, it was evident that the interference of $\mathrm{Fe}^{2+}$ and $\mathrm{Fe}^{3+}$ starts around $10.00 \mu \mathrm{M}$ and rises exponentially.
\end{abstract}

Keywords: MCR, Green synthesis, Fluorescent Chemo-sensor, Turn OFF-ON, Cobalt (II), indole derivatives

\section{Introduction}

Cobalt is a $3 \mathrm{~d}$ transition metal that is present in the human body as a trace element (Lee, 2007). Cobalt is the major constituent of vitamin B-12 (cobalamin), which is essential for making red blood cells in the body(Rickes et al., 1948). Cobalamin acts as a cofactor for two main human enzymes called methylmalonyl-CoA mutase and methionine synthase where both are highly important in maintaining health (Kräutler, 2012). Furthermore, cobalt is also involved in the biotin-dependent Krebs cycle which is the process that breakdown the sugars in the body (Yamada, 2013). However, excessive exposure to cobalt

*Correspondence: upulk@sjp.ac.lk

(C) University of Sri Jayewardenepura 
cause adverse health effects such as various systemic toxic reactions including severe effects to the cardiovascular system (Linna et al., 2020), peripheral and central nervous system (Catalani et al., 2012), endocrine system (Falfushynska et al., 2016), respiratory system(Linna et al. 2003), and skin diseases (Filon et al., 2013). Therefore, it is of great significance in monitoring its concentrations in the biological and environmental systems.

Zahir et al. reported a colorimetric method to determine trace levels of $\mathrm{Co}^{2+}$ in water bodies using complexation of $\mathrm{Co}^{2+}$ with 1-nitroso-2-naphthol-3.6-disulfonic acid disodium salt at a $\mathrm{pH}$ of 6.0. This method allowed the detection of $\mathrm{Co}^{2+}$ concentrations as low as $0.1 \mathrm{mg} / \mathrm{L}$ with no interference effects from the other cations at the provided conditions with greater accuracy (Zahir and Keshtkar, 1998). A highly sensitive colorimetric chemosensor based on coumarin conjugated thiocarbanohydrazone (CTC) was developed by Maity et $a l$. The CTC chemosensor was developed as a staining agent for $\mathrm{Co}^{2+}$ in cellular micro-organisms and worked in the visible region as a naked eye colorimetric sensor. The chemosensor exhibited a detection limit as low as $1 \mu \mathrm{M}$ in cobalt ion detection (Maity and Govindaraju, 2011).

Apart from the aforementioned techniques fluorometry is one of the spectrophotometric techniques with extraordinary sensitivity, higher specificity, and the ability to use in a wider concentration range (Karoui, 2016), which leads to metal ion detection through the development of a fluorometric probe. A typical fluorescent probe consists of at least one fluorescent core and a metal chelating moiety that will selectively bind with the metal ion of interest (Zheng et al., 2020). It was found that there is a lack of literature studies on the fluorescence chemosensors to detect cobalt via fluorescence enhancement due to the paramagnetic property of the $\mathrm{Co}^{2+}$ and the competitors such as $\mathrm{Ni}^{2+}, \mathrm{Cu}^{2+}$ and $\mathrm{Zn}^{2+}$ (Pal et al., 2014). Hence, this research has its uniqueness in developing a turn OFF-ON chemosensor to detect $\mathrm{Co}^{2+}$ via fluorescence enhancement. Abebe et al. designed TURN-ON fluorescein-based chemosensors that are highly selective and sensitive for $\mathrm{Co}^{2+}$ and $\mathrm{Ni}^{2+}$ in both absorption and emission modes. This fluorescent chemosensor was stable for over a month. Reversibility of the binding in the $\mathrm{Co}^{2+}$ and $\mathrm{Ni}^{2+}$ was studied using EDTA (Abebe et al., 2011).

The main mechanism regulating fluorescence enhancement due to paramagnetic metal ion binding is the process of photoinduced electron transfer-PET (Figure 1). An internal redox reaction takes place between the excited state of the fluorophore and the species that can donate electrons (receptor) during the photoinduced electron transfer (PET) mechanism. This is due to the high energy in the excited fluorophore which gives rise to improved oxidant and reductant properties (Yang et al., 2015). The PET takes place from lone pair of electrons in coordinating atoms like N, O, S, and P to that of the Singly Occupied Molecular Orbital (SOMO) of the fluorophore (which was the HOMO before the excitation of the electron) in fluorescent metal ion complexes. The coordinating metal ion will result in lowering the energy of the lone pair preventing PET to take place (Formica et al., 2012).

Paramagnetic metal ions like $\mathrm{Cu}^{2+}, \mathrm{Co}^{2+}, \mathrm{Ni}^{2+}, \mathrm{Fe}^{3+}$ speed up the intersystem crossing (ISC) which results in decreasing the fluorescence intensity in paramagnetic fluorescence quenching (Formica et al., 2012). This arises because once coordinated with the paramagnetic metal ion, the complex undergoes intersystem crossing (ISC) by excitation from S1 state to T1 state which is used to facilitate fluorescence quenching in biological and chemical sensors (Yang et al., 2015). 


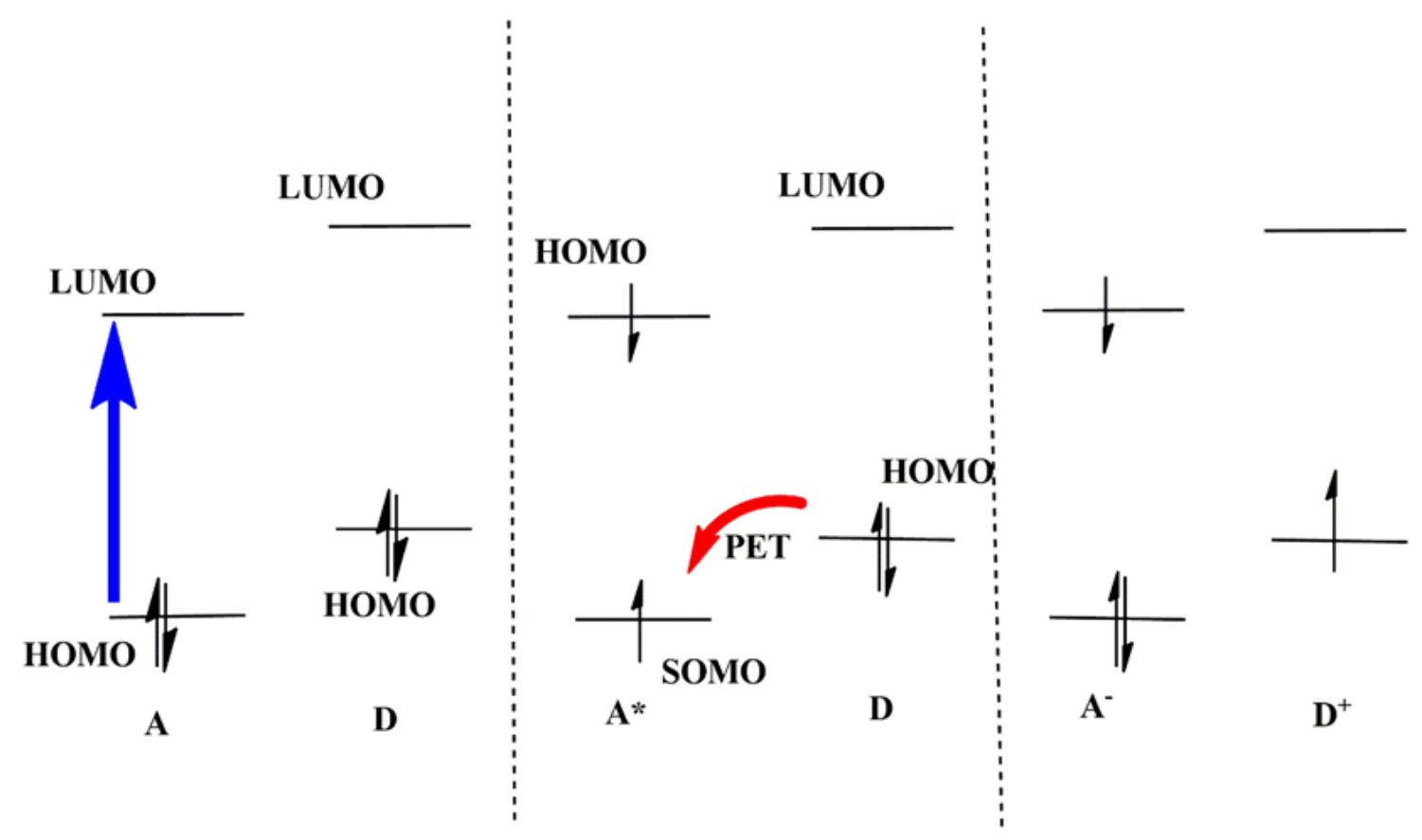

Figure 1. The energy level diagram from frontier orbital theory, illustrating PET mechanism for OFF state. A- acceptor (Fluorophore) D-donor(receptor).

Indole chemosensors are emerging in the field of chemosensors due to the Inherent fluorescent property of the indole chromophore (Dar et al., 2018). The substitution of electron-rich groups to an indole skeleton makes its affinity more towards cations rather than anions. The electron-donating ability and the extent of availability of the $\pi$ electron cloud to complex with the metal plays a major role in the cation affinity towards the indole moiety (Zhu et al., 2008). Particularly, this type of chemosensor should have the ability to interact with metal ions in the solution and change the prevailing fluorescence properties either by fluorescence enhancement or by fluorescence quenching in the solution to be effective in action (Anger et al., 2006, Rani, 2015).

Dar et al. demonstrated the chemosensor activity of 3-(phenyl (phenylthio) methyl)- $1 \mathrm{H}$-indole ligand towards $\mathrm{Cu}^{2+}$ and $\mathrm{Hg}^{2+}$ via fluorescence enhancement. The ligand was synthesized as a one-pot multicomponent reaction using indoles, aromatic aldehydes, and thiols at room temperature using hydrated ferric sulfate as the catalyst. The rigid binding of the ligand to the cations prevented the non-radiative fluorescence compared to the free ligand (Dar et al., 2018).

Furthermore, Kaur et al reported tris(N-methylindolyl)methane ligand showing "TURN OFF" fluorescence sensing towards the two cations $\mathrm{Cu}^{2+}$ and $\mathrm{Hg}^{2+}$. In this study, indole derivative was synthesized by the condensation reaction of $\mathrm{N}$-methyl indole and $\mathrm{N}$-methyl indole carboxaldehyde, catalyzed by ion-exchange resin amberlyst 15 (Kaur et al., 2011).

Shaik, Sharma et al synthesized N-((1H-indol-3-yl)(phenyl)methyl)aniline in water using polymer grafted $\mathrm{ZnO}$ nanoparticles as the catalyst while using indole, benzaldehyde and aniline as the starting materials. The reaction mixture was ultrasonicated to obtain a very high yield (i.e., 97\%) within 10 minutes

*Correspondence: upulk@ sjp.ac.lk

(C) University of Sri Jayewardenepura 
(Shaikh et al., 2019). Another research group introduced a novel approach to synthesize N-((1H-indol-3yl)(phenyl)methyl)aniline using indole, benzaldehyde, and nitrobenzene in water using indium catalyst in aqueous HCL. The reaction was conducted at room temperature resulting in an excellent yield (i.e., $96 \%$ ) within 40 minutes (Das et al., 2013). Lu, Wang et al synthesized the same 3-substituted indole derivative using indole, benzaldehyde and aniline as the starting materials and the reaction was carried out at 75-90 ${ }^{\circ} \mathrm{C}$ for 3 hours and a yield of 58\% was isolated ( $\mathrm{Lu}$ et al., 2019). To the best of our knowledge, there have been no reports for the synthesis of $\mathrm{N}-((1 \mathrm{H}-\mathrm{indol}-3-\mathrm{yl})(\mathrm{phenyl})$ methyl)aniline using hydrated ferric chloride catalyst under microwave irradiation which is described in this work.

Microwave-assisted organic synthesis (MAOS) is one of the major rising and revolutionizing areas in organic chemistry. MAOS has been identified as one of the major green synthesizing techniques (Ravichandran and Karthikeyan, 2011). Researches have been synthesizing these important derivatives of indole over the years using the conventional organic synthesis methods with major drawbacks such as side reactions, unnecessary byproducts, low yields, and time-consuming reactions (de la Hoz et al., 2005).

Lin et al synthesized 3-functionalized indole derivatives via a one-pot three-component domino reaction using anilines, arylglyoxal monohydrates, and 1,3-dicarbonyl compounds in a mixture of ethanol and water under MW irradiation. The reaction showed high regioselectivity $(100 \%)$ and short reaction times (i.e., $40 \mathrm{~min}$ ) which led to the generation of a large library of compounds with good to excellent yields (Lin et al., 2017).

We herein report a novel and efficient one-pot multicomponent green method to synthesis of a fluorometric probe, $\mathrm{N}-((1 \mathrm{H}-\mathrm{indol}-3-\mathrm{yl})(\mathrm{phenyl})$ methyl)aniline from indole, benzaldehyde, and aniline under microwave irradiation (Scheme 1). The sensing ability of the synthesized ligand was investigated using fluorescence spectroscopy.

\section{Experimental}

\subsection{Materials and methods}

Indole, aniline, benzaldehyde, ethanol, hydrated ferric chloride $\left(\mathrm{FeCl}_{3} \cdot 6 \mathrm{H}_{2} \mathrm{O}\right) \mathrm{CH}_{2} \mathrm{Cl}_{2}$, silica for thin-layer chromatography, anhydrous sodium sulfate, silica for column chromatography, hexane, acetone, $\mathrm{NaCl}, \mathrm{KCl}, \mathrm{BaCl}_{2}, \mathrm{CoCl}_{2} \cdot 6 \mathrm{H}_{2} \mathrm{O}, \mathrm{CdCl}_{2}, \mathrm{MnCl}_{2} .4 \mathrm{H}_{2} \mathrm{O}, \mathrm{CuCl}_{2}, \mathrm{ZnCl}_{2}, \mathrm{AgNO}_{3},\left(\mathrm{NH}_{4}\right)_{2} \mathrm{Fe}\left(\mathrm{SO}_{4}\right)_{2} \cdot 6 \mathrm{H}_{2} \mathrm{O}$, $\mathrm{NH}_{4} \mathrm{Fe}\left(\mathrm{SO}_{4}\right)_{2}$ were purchased from Sigma Aldrich with analytical grade. All chemicals were used as received without any further purification. The solutions of metals ions from $\mathrm{Na}^{+}, \mathrm{K}^{+}, \mathrm{Ba}^{2+}, \mathrm{Co}^{2+}, \mathrm{Cd}^{2+}$, $\mathrm{Mn}^{2+}, \mathrm{Cu}^{2+}, \mathrm{Zn}^{2+}, \mathrm{Ag}^{+}, \mathrm{Fe}^{2+}, \mathrm{Fe}^{3+}$ were prepared using distilled water. Solutions of ligand were prepared in methanol.

Reactions were carried out in a modified domestic microwave oven with $700 \mathrm{~W}$ under mediumlow power. The fluorescence emission spectra were recorded in Thermo Scientific Lumina Fluorescence Spectrometer. The ${ }^{1} \mathrm{H}$ NMR and ${ }^{13} \mathrm{C}$ NMR of the synthesized ligand were recorded using Bruker Ascend 400 spectrometer (Bruker, USA). Tetramethylsilane (TMS) was used as an internal reference and chemical shifts were reported as $\delta$ ppm units. Spectral data were presented as $\mathrm{s}=$ singlet, $\mathrm{d}=\mathrm{doublet}, \mathrm{t}=$ triplet, $\mathrm{q}=$ quartet, $\mathrm{m}=$ =multiplet, $\mathrm{br}=$ broad, app=apparent, coupling constant $(J)$ in $\operatorname{Hertz}(\mathrm{Hz})$. IR spectra are recorded by Attenuated Total Reflection- Fourier Transform Infrared (ATR-FTIR) spectroscopy on Thermo Scientific Nicolet S10 FT-IR spectrometer. Spectra were processed within $4000-500 \mathrm{~cm}^{-1}$. 


\subsection{Synthesis of $N-((1 H$-indol-3-yl)(phenyl)methyl)aniline $(L)$ under microwave irradiation}

In a $25.00 \mathrm{ml}$ round bottom flask, $3.0 \mathrm{ml}$ of ethanol was added to a mixture of indole $(0.117 \mathrm{~g}, 1$ mmol) and benzaldehyde $(0.01 \mathrm{ml}, 1 \mathrm{mmol})$ at room temperature. The hydrated ferric chloride $\left(\mathrm{FeCl}_{3} .6 \mathrm{H}_{2} \mathrm{O}, 0.027 \mathrm{~g}, 0.1 \mathrm{mmol}\right)$ was then added to the reaction mixture and stirred well. To the stirring solution, aniline $(0.11 \mathrm{ml}, 1.2 \mathrm{mmol})$ was added, and the resulting mixture was microwave irradiated for 8 minutes (Scheme 1). The progress of the reaction was monitored by TLC.

The reaction mixture was then cooled to room temperature. The residual ethanol was removed using a rotary evaporator and the crude residue was extracted with dichloromethane $(2 \times 15.0 \mathrm{ml})$. The organic layer was washed with distilled water, dried over anhydrous sodium sulfate $\left(\mathrm{Na}_{2} \mathrm{SO}_{4}\right)$, and it was concentrated in a rotary evaporator. Finally, the crude residue was purified by a silica gel column chromatography (dichloromethane: hexane $=1: 1$ ) to afford a reddish-orange oil with a $92 \%$ yield.

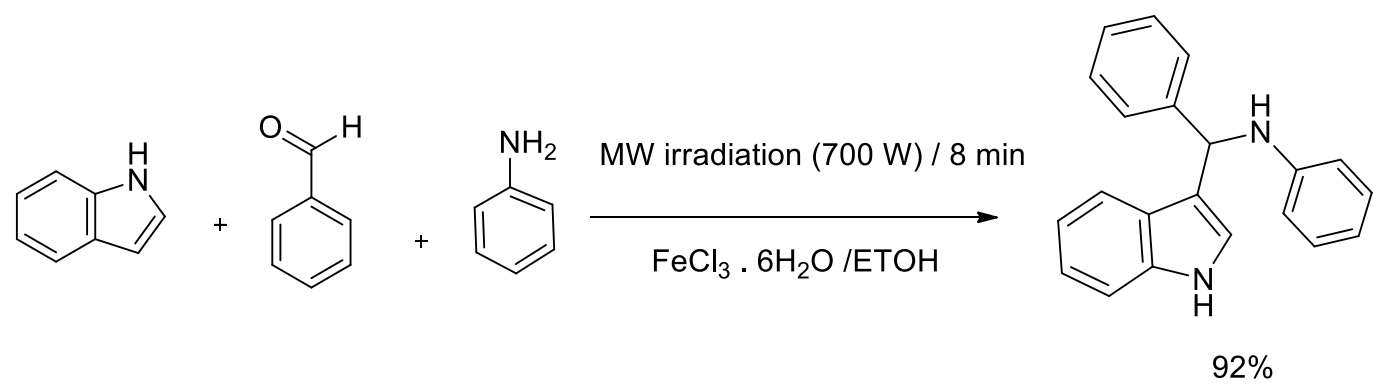

Scheme 1. Synthesis of $N-((1 \mathrm{H}-\mathrm{indol}-3-y \mathrm{l})($ phenyl)methyl)aniline.

\subsection{Cation recognition studies}

Exactly $30.00 \mu \mathrm{M}$ solutions were prepared for $\mathrm{Na}^{+}, \mathrm{K}^{+}, \mathrm{Mn}^{2+}, \mathrm{Fe}^{2+}, \mathrm{Fe}^{3+}, \mathrm{Ni}^{2+}, \mathrm{Co}^{2+}, \mathrm{Cu}^{2+}$ and, $\mathrm{Zn}^{2+}$ in distilled water to determine the fluorescence intensity change. A solution of $30.00 \mu \mathrm{M} \mathrm{N}-((1 \mathrm{H}-$ indol-3-yl)(phenyl)methyl)aniline ligand (L) was prepared in methanol. Exactly $10.00 \mathrm{ml}$ of each metal ion solution and the ligand (L) were mixed while maintaining the $\mathrm{pH}$ at 3.5. The fluorescence spectra were recorded at room temperature at an excitation wavelength of $369 \mathrm{~nm}$.

\subsection{Determination of ligand: $\mathrm{Co}^{2+}$ stoichiometric ratio}

The stoichiometric ratio of Ligand: $\mathrm{Co}^{2+}$ was determined by Job's method of continuous variation. (Olson and Bühlmann, 2011). Stock solutions of $\mathbf{L}$ in methanol ( $30.00 \mu \mathrm{M}$ ) and $\mathrm{Co}^{2+}$ in distilled water $(30.00 \mu \mathrm{M})$, was prepared at room temperature. Then 1.00, 2.00, 3.00, 4.00, 5.00, 6.00, 7.00, 8.00 and 9.00 $\mathrm{mL}$ of the stock solution of $\mathbf{L}$ were mixed with 9.00, 8.00, 7.00, 6.00, 5.00, 4.00, 3.00, 2.00 and $1.00 \mathrm{ml}$ of $\mathrm{Co}^{2+}$ solution, to obtain molar fraction of $\mathbf{L}$ as $0.1,0.2,0.3,0.4,0.5,0.6,0.7,0.8$ and 0.9 respectively,

*Correspondence: upulk@sjp.ac.lk

(C) University of Sri Jayewardenepura 
at $\mathrm{pH}$ 3.5. The fluorescence emission spectra were recorded after mixing the two solutions thoroughly. the stoichiometric coefficient between $(\mathbf{L})$ and $\mathrm{Co}^{2+}$ was determined using Job's plot (Vashisht et al., 2019).

\section{Results and discussion}

\subsection{Microwave-assisted synthesis of $\mathrm{N}-((1 \mathrm{H}$-indol-3yl)(phenyl)methyl)aniline sensor}

The ligand was synthesized from readily available starting materials using a one-pot multicomponent reaction under microwave irradiation and the optimum yield (i.e.,92\%) was obtained after 8 minutes of MW irradiation. However, the reaction has not been completed even after five hours at room temperature and the product was obtained at a very low yield (i.e.,22\%).

The only byproduct formed in this reaction is one equivalent of water which is an innocuous byproduct that does not require any further treatments. Due to the highly convergent nature of the multicomponent reactions, maximum incorporation of the reactant materials in the product leads to a significantly high atom economy. A very high atom economy of $94 \%$ was obtained for this synthesis which also indicates the minimal byproduct formation. According to the environment, health, and safety (EHS) approach (Capello et al., 2007) the solvent used in this synthesis, ethanol, provides a lower score which indicates low environmental and health hazards. Furthermore, the synthesis was performed in a modified domestic microwave oven. The reactions performed in microwave heating technology represent a green chemistry protocol by utilizing the reaction conditions, preventing waste, exhibiting energy efficiency, and minimizing the reaction time and accidents.

\subsubsection{Spectral data for $N-((1 H$-indol-3-yl)(phenyl)methyl)aniline}

Reddish orange viscous oil;- yield :92\% (0.275 g) $\mathrm{R}^{\mathrm{f}}$ (Hexane: DCM 1:1)=0.51, FT-IR (ATR) $\left(v_{\max } / \mathrm{cm}^{-1}\right)$ : $3408(\mathrm{w}), 3054(\mathrm{~b}), 1616(\mathrm{~m}), 1455(\mathrm{w}), 1336(\mathrm{w}), 1216(\mathrm{w}), 1174(\mathrm{w}), 1109(\mathrm{w}), 738(\mathrm{~m})$, $692(\mathrm{~m}) .{ }^{1} \mathrm{H}$ NMR $(400 \mathrm{MHz}$, Acetone-D6) : $\delta 4.55(\mathrm{~s}, 1 \mathrm{H}, \mathrm{NH}), 5.94$ (s, 1H ) 6.58 (ddt, J= 7.4, 6.3,1.0 $\mathrm{Hz}, 1 \mathrm{H}), 6.71-6.61(\mathrm{~m}, 2 \mathrm{H}), 6.86-6.75(\mathrm{~m}, 1 \mathrm{H}), 6.91(\mathrm{ddd}, J=8.0,7.0,1.0 \mathrm{~Hz}, 1 \mathrm{H}), 7.12-6.98(\mathrm{~m}$, $3 \mathrm{H}), 7.26-7.15(\mathrm{~m}, 1 \mathrm{H}), 7.32-7.26(\mathrm{~m}, 2 \mathrm{H}), 7.51-7.32(\mathrm{~m}, 4 \mathrm{H}), 10.00(\mathrm{~s}, 1 \mathrm{H}, \mathrm{NH}),{ }^{13} \mathrm{C}$ NMR $(101$ $\mathrm{MHz}$, Acetone-D6) $\delta$ 149.3, 146.0, 138.1, 129.5 (2C), 128.9 (2C), 128.1 (2C), 126.7, 124.6, 122.1, 120.3, $119.9,119.3,117.5,115.2(2 \mathrm{C}), 114.3,112.12,41.2$. The spectroscopic data match with those reported in the literature (Lu et al., 2019, Shaikh et al., 2019).

\subsubsection{The proposed mechanism for the synthesis of the ligand}

The proposed mechanism for the synthesis of the ligand is shown in Scheme 2. An iminium ion intermediate is formed when the aniline is reacted with benzaldehyde in ethanol which is then attacked by the $\mathrm{C}-3$ center of the indole to obtain the 3-substituted indole product. A new C-C bond and a C-N bond are formed during the reaction with the formation of a new chiral center (Srihari et al. 2009). The stoichiometric ratio of the reactants is highly important because the excess indole in the presence of aldehyde and catalyst leads to the formation of bis-indole methane derivatives (Khorshidi and Shariati, 2014, Tocco et al., 2017). 


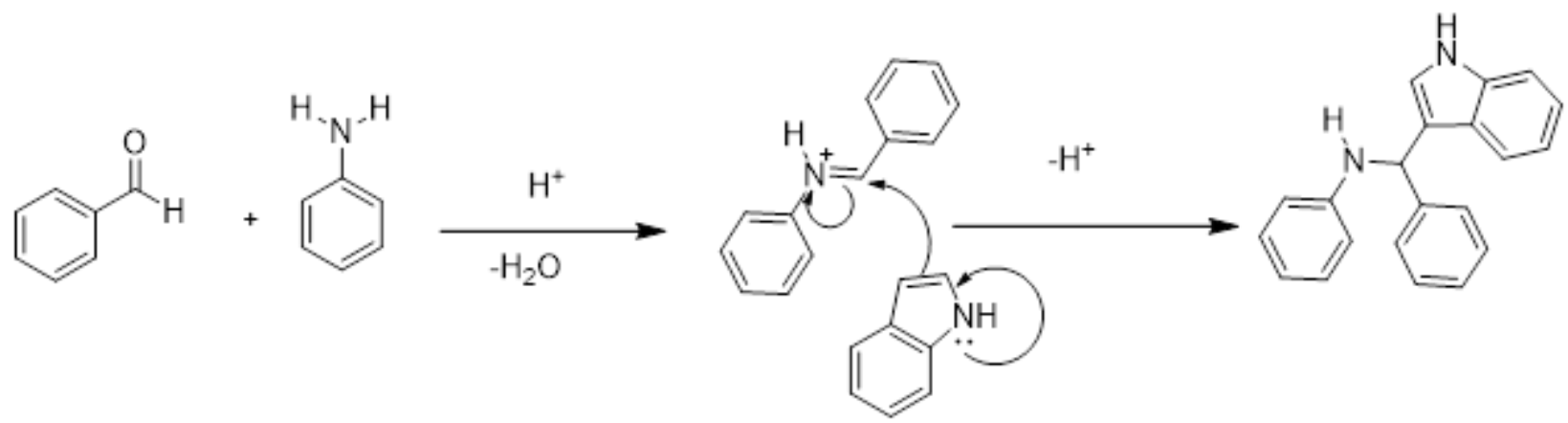

Scheme 2. Proposed reaction mechanism of synthesis of $N$ - $((1 \mathrm{H}-\mathrm{indol}-3$-yl)(phenyl)methyl)aniline sensor.

\subsection{Selectivity of the ligand toward cations}

The fluorescence measurements of the synthesized ligand were carried out using a fluorescence spectrometer. Ligand showed no considerable fluorescence activity in the range of 250-380 nm. A significant fluorescence enhancement was observed for the ligand in the presence of the $\mathrm{Co}^{2+}$ where other cations such as $\mathrm{Na}^{+}, \mathrm{K}^{+}, \mathrm{Mn}^{2+}, \mathrm{Ni}^{2+}, \mathrm{Cu}^{2+}, \mathrm{Zn}^{2+}$, and $\mathrm{Ag}^{+}$showed very low-intensity fluorescence enhancements. $\mathrm{Fe}^{2+}$ and $\mathrm{Fe}^{3+}$ showed mild fluorescence compared to the $\mathrm{Co}^{2+}$. The relevant peak intensities to the $\mathbf{L}$-metal ion complexes are shown in Figure 2. The maximum error value observed was less than $5 \%$.

Based on the fluorescence intensity values for the different cations, the ionic radius of the $\mathrm{Co}^{2+}$ is in the optimum range among the tested cations indicating the optimal interaction of $\mathrm{Co}^{2+}$ with the ligand in the complex. Since the fluorescence changes occurred in the UV region $(<400 \mathrm{~nm})$, any visible color change was not observed throughout the fluorescence analysis. It was observed that the fluorescence of the ligand was enhanced by 160 fold with the $30.00 \mu \mathrm{M} \mathrm{Co}^{2+}$ solution.

The initial "OFF" fluorescence quenched state of the ligand can be described using photoinduced electron transfer (PET). The coordination of $\mathrm{Co}^{2+}$ and the receptor site of the ligand restrain the PET processes (Colenda et al., 2018). The redox potential of the donor is increased upon cation binding to the ligand. Hence fluorescence quenching is suppressed due to lowering of HOMO energy which makes PET not possible any further (Valeur and Leray, 2000). The changes in the charge density on the N-binding site of the ligand after coordinating with $\mathrm{Co}^{2+}$ inhibit the PET mechanism (Liu et al., 2019). The rigidity of the $\mathrm{L}_{-} \mathrm{Co}^{2+}$ complex is higher than to the free ligand, which gives rise to the Chelation enhanced fluorescence (Liu et al., 2019). The fluorescence enhancement of $\mathrm{Co}^{2+}$ with the ligand is a special case scenario because $\mathrm{Co}^{2+}$ is a paramagnetic metal ion with a $\mathrm{d}^{7}$ configuration which normally quenches the intrinsic fluorescence.

This special phenomenon is explained by Ramachandram et al. for a few 1,8- naphthalimide derivatives induced by transition metal salts (Ramachandram et al., 2000). The interaction between the fluorophore and the $\mathrm{Co}^{2+}$ leads to fluorescence quenching whereas the interaction between the receptor site of the fluorophore and the $\mathrm{Co}^{2+}$ ions leads to fluorescence enhancement. Hence, the net effect of these opposing features is determined by the extent of quenching due to the fluorophore - metal ion interaction and the enhancement due to metal ion- receptor site interaction. This may be supported by the suitable

*Correspondence: upulk@sjp.ac.lk

(C) University of Sri Jayewardenepura 
coordination geometry of the $\mathrm{N}-((1 \mathrm{H}-\mathrm{indol}-3-\mathrm{yl})(\mathrm{phenyl})$ methyl)aniline, the appropriate ionic radius of the $\mathrm{Co}^{2+}$ and adequate binding energy of the ligand to the $\mathrm{Co}^{2+}$ (Wang et al., 2018).

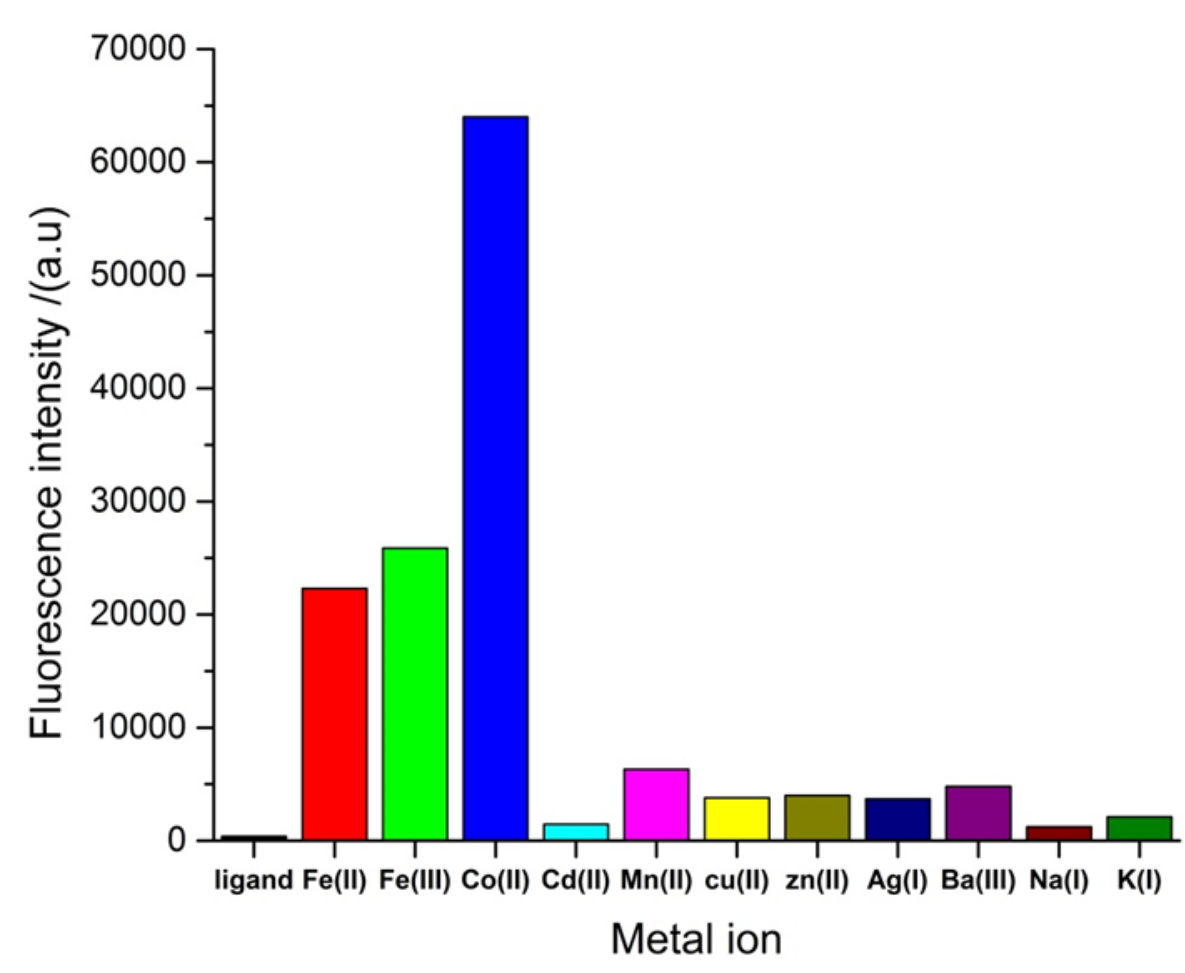

Figure 2. The fluorescence intensity of the ligand $(30.00 \mu \mathrm{M})$ in the presence of various metal cations.

$*$ slit width $=20 \mathrm{~nm}$ at $369 \mathrm{~nm}($ error $<5 \%)$.

\subsection{Determination of stoichiometric coefficient by Job's plot}

A Job's plot was performed to determine stoichiometry between $\mathbf{L}$ and the $\mathrm{Co}^{2+}$ cation. The maximum fluorescence intensity was observed at 0.65 molar ratio confirming the $2: 1$ stoichiometric ratio of $\mathbf{L}$ to $\mathrm{Co}^{2+}$ (Figure 03).

The optical properties of the $\mathbf{L}-\mathrm{Co}^{2+}$ complex showed that there is no overlap between the absorption and the fluorescence emission spectra. Stokes shift $\Delta \lambda$ was found to be $93 \mathrm{~nm}$ which was a considerably greater value for a single fluorophore. A greater stoke shift value minimizes self-quenching which will be significant for analytical purposes (Saleh et al., 2019). 


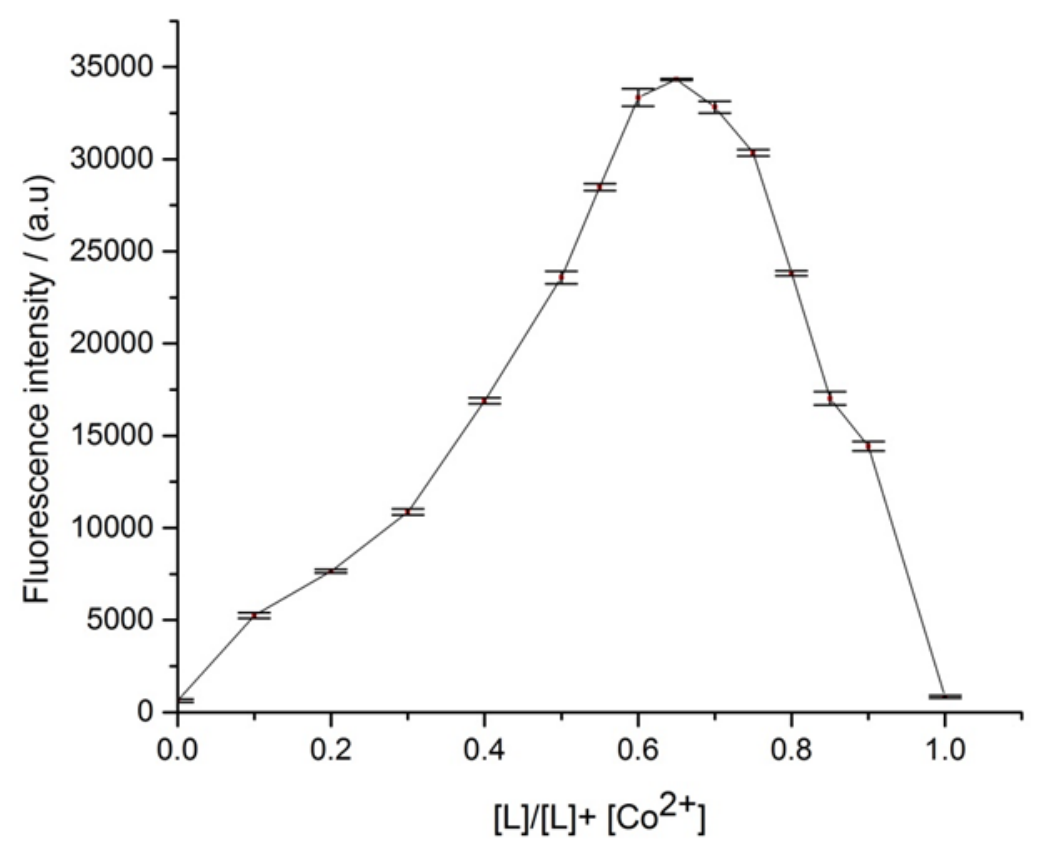

Figure 3. Job's plot depicting the binding ratio between the ligand and $\mathrm{Co}^{2+}$ ion.

\subsection{Sensitivity studies}

The sensitivity studies of $\mathrm{N}-\left(\left(1 \mathrm{H}\right.\right.$-indol-3yl)(phenyl)methyl)aniline sensor towards $\mathrm{Co}^{2+}$ were investigated by fluorescence titration experiments which were carried out by monitoring of fluorescence intensity changes upon the addition of various concentrations of $\mathrm{Co}^{2+}$ (from $0-70 \mu \mathrm{M}$ ) to the indole sensor $(30.00 \mu \mathrm{M} /$ in $\mathrm{MeOH} /$ at $\mathrm{pH} 3.5)$ at an excitation wavelength of $369 \mathrm{~nm}$ (Figure 4). It was observed that the intensity of the fluorescence enhancement increases with the increase of $\mathrm{Co}^{2+}$ concentration and showed a hyperchromic shift. The fluorescence intensity enhancements were leveled off closer to $70 \mu \mathrm{M}$. This can be due to the stronger suppression of the PET mechanism of the ligand by increasing the $\mathrm{Co}^{2+}$ concentration of the medium. (Ashokkumar et al., 2011, Gao et al., 2020).

The detection limit of the indole sensor was determined using the slope of a fluorescence intensity vs concentration of $\mathrm{Co}^{2+}$ and a threefold standard deviation of the lowest concentration of the calibration curve (blank solution)(Skoog et al. 2013). The detection limit is $2.2 \mu \mathrm{M}$ (Figure 5) which is comparable to the reported values of $\mathrm{Co}^{2+}$ chemosensors such as coumarin (Vashisht et al., 2019), diethylenetriamine (Lee et al. 2016), oxadiazole (Wang et al., 2011), pyridine systems (Na et al., 2016), pyrazine coupled rhodamine(Liu et al. 2017) derivatives. The $\mathrm{Co}^{2+}$ induced fluorescence intensity enhancement showed excellent linearity with a correlation coefficient of $\mathrm{R}^{2}=0.99$ in the range of $0.50-80.00 \mu \mathrm{M}$. This indicates a wide linear range of chemosensor action in favor of detecting $\mathrm{Co}^{2+}$ in the actual quantitative measurements.

*Correspondence: upulk@sjp.ac.lk

(C) University of Sri Jayewardenepura 


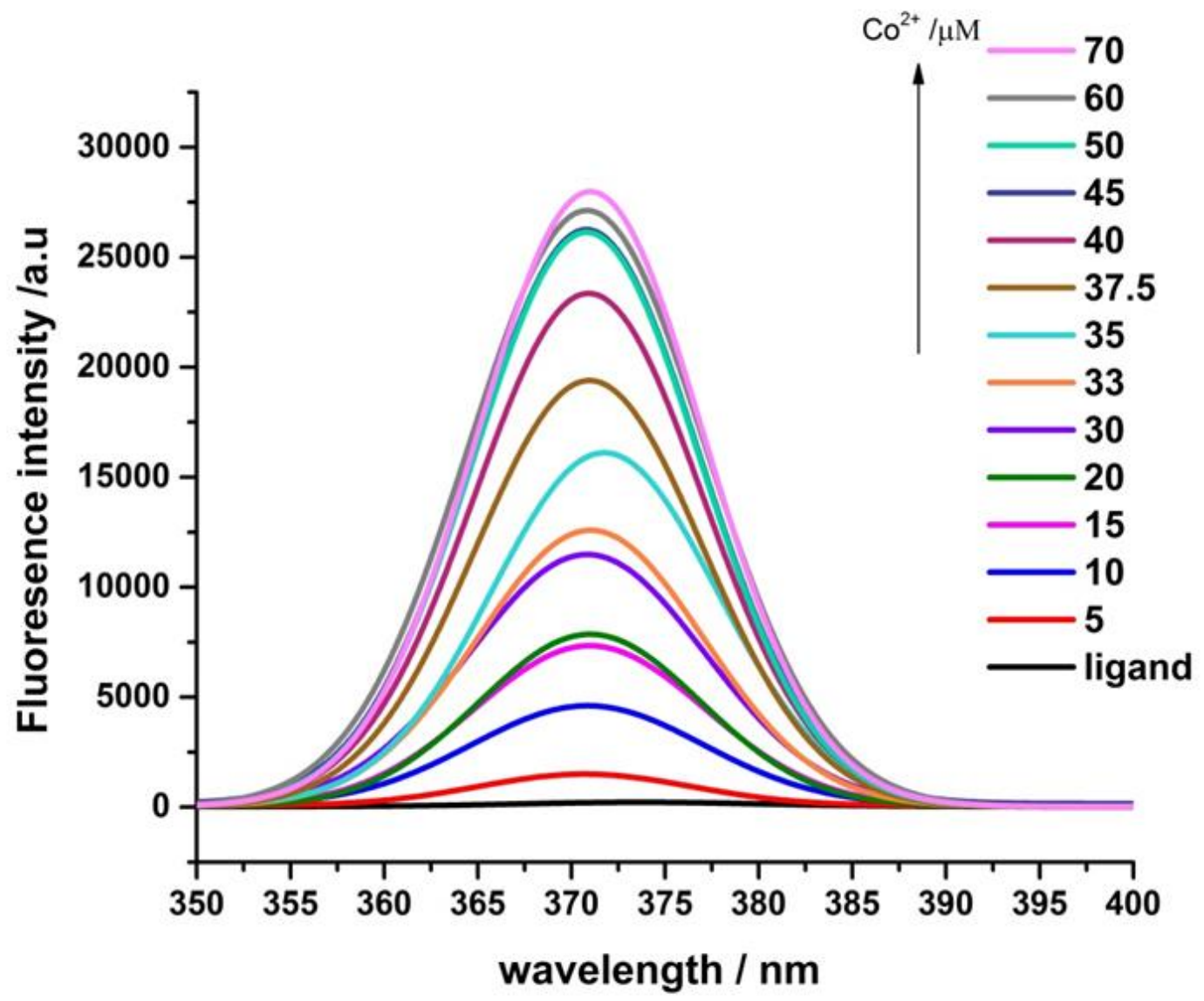

Figure 4. Fluorescence intensity change of the ligand $(30.00 \mu \mathrm{M})$ with the increase of the $\mathrm{Co}^{2+}$ concentration. 


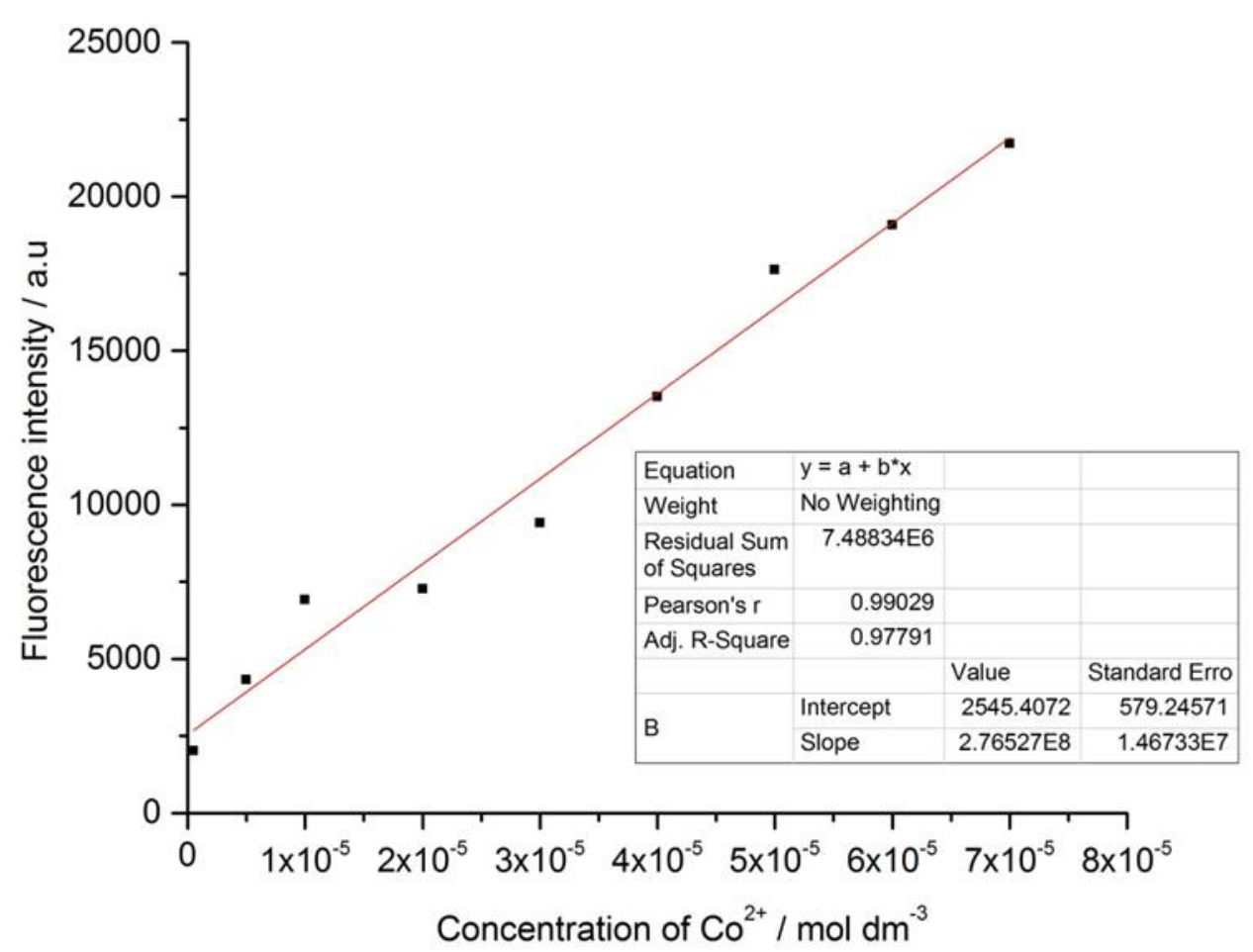

Figure 5. The calibration curve of the fluorescence intensity versus $\left[\mathrm{Co}^{2+]}\right.$ at $\mathrm{pH} 3.5$ (all the error values calculated were less than $1 \%$ ).

\subsection{Interference study}

A competition ion study was performed to determine the interference effect from other cations to the $\mathbf{L}-\mathrm{Co}^{2+}$ complex (Aich et al., 2015). A solution series were prepared in test tubes where each contains $\mathrm{Co}^{2+}: \mathbf{L}$ in a 1:2 ratio $(10.00 \mu \mathrm{M} / \mathrm{pH}-3.5)$. The fluorescence readings were measured after adding the cations $\mathrm{Na}^{+}, \mathrm{K}^{+}, \mathrm{Mn}^{2+}, \mathrm{Fe}^{2+}, \mathrm{Fe}^{3+}, \mathrm{Ni}^{2+}, \mathrm{Cu}^{2+}, \mathrm{Zn}^{2+}$ of $10.00 \mu \mathrm{M}$ separately to the ligand respectively. In this study, it was observed that the fluorescence intensities obtained for the $\mathbf{L}-\mathbf{C o}^{2+}$ complex were unaffected in the presence of metal cations such as $\mathrm{Mn}^{2+}, \mathrm{Cu}^{2+}, \mathrm{Cd}^{2+}, \mathrm{Ba}^{2+}, \mathrm{Ag}^{+}, \mathrm{Zn}^{2+}$, and $\mathrm{Na}^{+}$. It was observed that fluorescence intensity enhancement was observed in the presence of $\mathrm{Fe}^{2+}$ and $\mathrm{Fe}^{3+}$ ions in the medium (Figure 6). Other metal ions caused ignorable perturbation on the fluorescence intensity measurements. Hence it can be concluded that there is an interference effect from $\mathrm{Fe}^{2+}$ and $\mathrm{Fe}^{3+}$ to the detection of $\mathrm{Co}^{2+}$.

The extent of the interference effect from $\mathrm{Fe} 2+$ and $\mathrm{Fe} 3+$ was further investigated by measuring fluorescence intensities of $10.00 \mu \mathrm{M}$ ligand and $10.00 \mu \mathrm{M} \mathrm{Co} 2+$ solutions with increasing $\mathrm{Fe} 2+/ \mathrm{Fe} 3+$ concentrations (Figure.7). It was observed that the interference starts from about $10.00 \mu \mathrm{M}$ for both the Fe 2+ and $\mathrm{Fe} 3+$ up concentration and rises exponentially.

*Correspondence: upulk@sjp.ac.lk

(C) University of Sri Jayewardenepura 


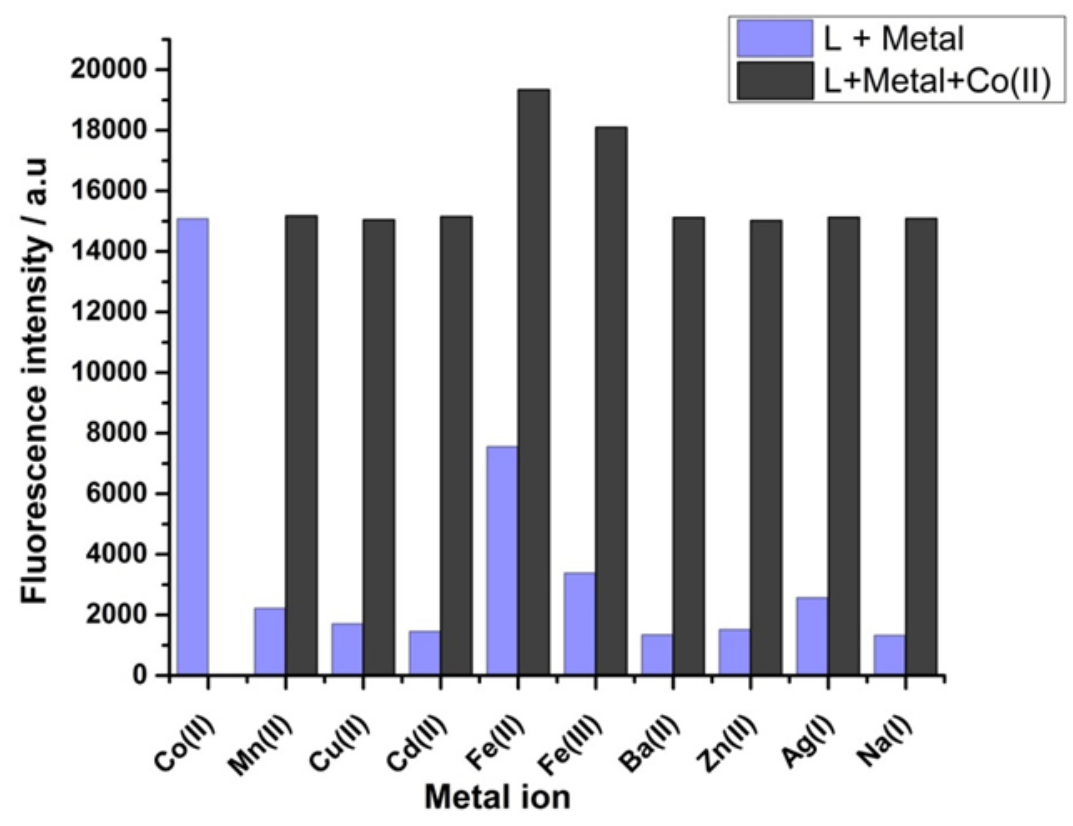

Figure 6. Metal ion selectivity of the $\mathbf{L}(10.00 \mu \mathrm{M})$ in $\mathrm{MeOH}$ solution. (the blue bars represent the fluorescent intensity of $\mathbf{L}$ in the presence of metal ion of interest $(10.00 \mu \mathrm{M})$ in 2:1 ratio, and the black bars represent the changes of fluorescent intensity that occurs upon the subsequent addition of $10.00 \mu \mathrm{M}$ $\mathrm{Co}^{2+}$ to the above solution).

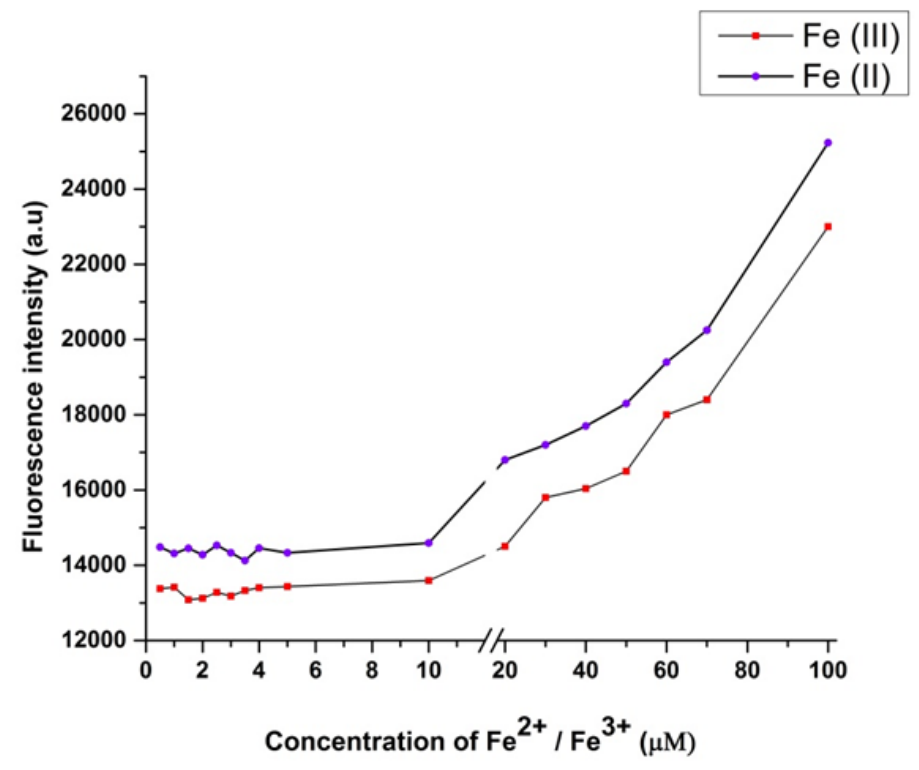

Figure 7. Fluorescence intensity variation of $\mathrm{L}-\mathrm{Co}^{2+}$ in the presence of $\mathrm{Fe}^{2+}$ and $\mathrm{Fe}^{3+}$. 


\section{Conclusion}

An indole-based fluorometric turn OFF-ON chemosensor for the detection of $\mathrm{Co}^{2+}$ was synthesized using an efficient one-pot multicomponent, green method under microwave irradiation. An excellent yield (i.e.,92\%) was obtained within 8 minutes of microwave irradiation.

The synthesized ligand, $N-((1 \mathrm{H}-$ indol-3-yl)(phenyl)methyl)aniline showed a significantly high "TURN ON" fluorescence emission in the presence of $\mathrm{Co}^{2+}$ suppressing the prevailing PET mechanism. The extremely high linear dependency of the Benesi Hildebrand plot synchronized with the results of Job's plot analysis where it indicated a stoichiometric coefficient of 2:1. It was found that the low detection limit of the ligand is in the micro-molar range $(2.2 \mu \mathrm{M})$ which is in accordance with the previously developed chemosensors for $\mathrm{Co}^{2+}$. Further, it was revealed that $\mathrm{Fe}^{2+}$ and $\mathrm{Fe}^{3+}$ are acting as interfering agents to the chemosensor activity of the ligand.

\section{Acknowledgment}

Department of Chemistry, Faculty of Applied Sciences, University of Sri Jayewardenepura, Sri Lanka

\section{References}

Abebe, F. A., Eribal, C. S.., Ramakrishna, G., Sinn, E., 2011. A ‘turn-on’ fluorescent sensor for the selective detection of cobalt and nickel ions in aqueous media. Tetrahedron Letters 52(43), 55545558.

Aich, K., Goswami, S., Das, S., Mukhopadhyay, C. D., 2015. A new ICT and CHEF based visible light excitable fluorescent probe easily detects in vivo $\mathrm{Zn}^{2+}$. RSC Advances. 5(39), 31189-31194.

Alamgir, S., Rhaman, M. M., Basaran, I., Powell, D. R., Hossain, M. A., 2020. Colorimetric and spectroscopic cobalt (II) sensing by a simple Schiff base. Polyhedron. 187, 114681.

Anger, P., Bharadwaj, P., Novotny, L., 2006. Enhancement and quenching of single-molecule fluorescence. Physical review letters. 96(11), 113002.

Ashokkumar, P., Ramakrishnan, V., Ramamurthy, P., 2011. Photoinduced electron transfer (PET) based $\mathrm{Zn} 2+$ fluorescent probe: transformation of turn-on sensors into ratiometric ones with dual emission in acetonitrile. The Journal of Physical Chemistry A. 115(50), 14292-14299.

Capello, C., Fischer, U., Hungerbühler, K., 2007. What is a green solvent? A comprehensive framework for the environmental assessment of solvents. Green Chemistry. 9(9), 927-934.

Catalani, S., Rizzetti, M., Padovani, A., Apostoli, P., 2012. Neurotoxicity of cobalt. Human \& experimental toxicology. 31(5), 421-437.

Colenda, B. E., Lee, H.-S., Reibenspies, J. H., Hancock, R. D., 2018. Indole-based fluorescence sensors for both cations and anions. Inorganica Chimica Acta. 482, 478-490.

Dar, A. A., Dwivedi, A. K., Iyer, P. K., Khan, A., 2018. Indole derived "turn-on" fluorometric probe for dual detection of $\mathrm{Hg}^{2+}$ and $\mathrm{Cu}^{2+}$ ions at nanomolar level. Asian Journal of Green Chemistry. 2(3. pp. 171-280), 171-180.

Das, B., Kumar, J. N., Kumar, A. S., Satyalakshmi, G., Shinde, D. B., 2013. A distinct novel approach for the synthesis of 3-indolyl-methanamines starting from indoles, aldehydes and nitrobenzenes in water. RSC advances. 3(34), 14308-14311.

de la Hoz, A., Diaz-Ortiz, A., Moreno, A., 2005. Microwaves in organic synthesis. Thermal and nonthermal microwave effects. Chemical Society Reviews. 34(2), 164-178.

*Correspondence: upulk@sjp.ac.lk

(C) University of Sri Jayewardenepura 
Falfushynska, H., Gnatyshyna, L., Fedoruk, O., Sokolova, I. M., Stoliar, O., 2016. Endocrine activities and cellular stress responses in the marsh frog Pelophylax ridibundus exposed to cobalt, zinc and their organic nanocomplexes. Aquatic Toxicology. 170, 62-71.

Filon, F. L., Crosera, M., Timeus, E., Adami, G., Bovenzi, M., Ponti, J., Maina, G., 2013. Human skin penetration of cobalt nanoparticles through intact and damaged skin. Toxicology in Vitro. 27(1), 121-127.

Formica, M., Fusi, V., Giorgi, L., Micheloni, M., 2012. New fluorescent chemosensors for metal ions in solution. Coordination Chemistry Reviews. 256(1-2), 170-192.

Gao, L.L., Li, S.P., Wang, Y., Wu, W.N., Zhao, X.L., Li, H.J., Xu, Z.H., 2020. Quinoline-based hydrazone for colorimetric detection of $\mathrm{Co}^{2+}$ and fluorescence turn-on response of $\mathrm{Zn}^{2+}$. Spectrochimica Acta. Part A: Molecular and Biomolecular Spectroscopy. 230, 118025.

Karoui, R., 2016. Quality Control in Food Processing. Encyclopedia of Food and Health. B.. Oxford, Academic Press. 567-572.

Kaur, P., Kaur, S., Singh, K.., Sharma, P. R., Kaur, T., 2011. Indole-based chemosensor for $\mathrm{Hg}^{2+}$ and $\mathrm{Cu}^{2+}$ ions: applications in molecular switches and live cell imaging. Dalton Transactions. 40(41), 10818-10821.

Khan, T., Sheoran, M., Raj, N., Jain, S., Gupta, D., Naik, S., 2017. Screening of biologically important $\mathrm{Zn}^{2+}$ by a chemosensor with fluorescent turn on - off mechanism. Spectrochimica Acta Part A: Molecular and Biomolecular Spectroscopy. 189.

Khorshidi, A., Shariati, S., 2014. Sulfuric acid functionalized MCM-41 coated on magnetite nanoparticles as a recyclable core-shell solid acid catalyst for three-component condensation of indoles, aldehydes and thiols. RSC advances. 4(78), 41469-41475.

Kräutler, B., 2012. Biochemistry of B12-cofactors in human metabolism. Water Soluble Vitamins. 323346.

Lee, J., 2007. Concise inorganic cheemistry, $5^{\text {th }}$ ed, Blackwell.

Lee, S. Y., Kim, S. Y., Kim, J. A., Kim, C., 2016. A dual chemosensor: Colorimetric detection of $\mathrm{Co}^{2+}$ and fluorometric detection of Zn2+. Journal of Luminescence. 179, 602-609.

Lin, W., Zheng, Y.X., Xun, Z., Huang, Z.B., Shi, D.Q., 2017. Microwave-assisted regioselective synthesis of 3-functionalized indole derivatives via three-component domino reaction. ACS combinatorial science. 19(11), 708-713.

Linna, A., Oksa, P., Palmroos, P., Roto, P., Laippala, P., Uitti, J., 2003. Respiratory health of cobalt production workers. American journal of industrial medicine. 44(2), 124-132.

Linna, A., Uitti, J., Oksa, P., Toivio, P., Virtanen, V., Lindholm, H., Halkosaari, M., Sauni, R., 2020. Effects of occupational cobalt exposure on the heart in the production of cobalt and cobalt compounds: a 6-year follow-up. International archives of occupational and environmental health. 93(3), 365-374.

Liu, K., Guo, P., Liu, L., Shi, X., 2017. Fluorescence enhancement of a novel pyrazine coupled rhodamine derivative for the paramagnetic $\mathrm{Co}^{2+}$ detection. Sensors and Actuators B: Chemical. 250, 667-672.

Liu, Y.-L., Yang, L., Li, L., Guo, Y. Q., Pang, X.X., Li, P., Ye, F., Fu, Y., 2019. A new fluorescent chemosensor for cobalt (II) ions in living cells based on 1, 8-naphthalimide. Molecules. 24(17), 3093.

Lu, A., Wang, T., Hui, H., Wei, X., Cui, W., Zhou, C., Li, H., Wang. Z., Guo, J., Ma, D., Wang, Q., 2019. Natural Products for Drug Discovery: Discovery of Gramines as Novel Agents against a Plant Virus. Journal of Agricultural and Food Chemistry. 67(8), 2148-2156. 
Maity, D., T. Govindaraju., 2011. Highly selective colorimetric chemosensor for $\mathrm{Co}^{2+}$. Inorganic chemistry. 50(22), 11282-11284.

Na, Y. J., Y. W. Choi., G. R. You., C. Kim., 2016. A novel selective colorimetric chemosensor for cobalt ions in a near perfect aqueous solution. Sensors and Actuators B: Chemical. 223, 234-240.

Olson, E. J., P. Bühlmann., 2011. Getting More out of a Job Plot: Determination of Reactant to Product Stoichiometry in Cases of Displacement Reactions and n:n Complex Formation. The Journal of Organic Chemistry. 76(20), 8406-8412.

Pal, S., N. Chatterjee., P. K. Bharadwaj., 2014. Selectively sensing first-row transition metal ions through fluorescence enhancement. RSC advances. 4(51): 26585-26620.

Park, G. J., J. J. Lee., G. R. You., L. Nguyen., I. Noh., C. Kim., 2016. A dual chemosensor for $\mathrm{Zn}^{2+}$ and $\mathrm{Co}^{2+}$ in aqueous media and living cells: Experimental and theoretical studies. Sensors and Actuators B: Chemical. 223, 509-519.

Ramachandram, B., G. Saroja., B. Sankaran., A. Samanta., 2000. Unusually high fluorescence enhancement of some 1, 8-naphthalimide derivatives induced by transition metal salts. The Journal of Physical Chemistry B. 104(49), 11824-11832.

Rani, P., 2015. Chemosensor and its applications. IRJRR 3: 1-10.

Ravichandran, S., E. Karthikeyan., 2011. Microwave synthesis-a potential tool for green chemistry. Int J Chem Tech Res. 3(1), 466-470.

Rickes, E. L., N. G. Brink., P. Koniuszy., T. R. Wood., K. Folkers., 1948. Vitamin B12, a cobalt complex. Science (Washington). 108.

Saleh, S. M., R. Ali., F. Alminderej., I. A. Ali., 2019. Ultrasensitive optical chemosensor for Cu (II) detection. International journal of analytical chemistry. 2019.

Shaikh, T., A. Sharma., H. Kaur., 2019. Ultrasonication-Assisted Synthesis of 3-Substituted Indoles in Water Using Polymer Grafted ZnO Nanoparticles as Eco-Friendly Catalyst. ChemistrySelect. 4(1), 245-249.

Skoog, D. A., D. M. West., F. J. Holler., S. R. Crouch., 2013. Fundamentals of analytical chemistry, Cengage learning.

Srihari, P., V. K. Singh., D. C. Bhunia., J. Yadav., 2009. One-pot three-component coupling reaction: solvent-free synthesis of novel 3-substituted indoles catalyzed by PMA-SiO2. Tetrahedron Letters. 50(27), 3763-3766.

Tocco, G., G. Zedda., M. Casu., G. Simbula., M. Begala., 2017. Solvent-free addition of indole to aldehydes: Unexpected synthesis of novel 1-[1-(1H-indol-3-yl) alkyl]-1h-indoles and preliminary evaluation of their cytotoxicity in hepatocarcinoma cells. Molecules. 22(10), 1747.

Valeur, B., I. Leray., 2000. Design principles of fluorescent molecular sensors for cation recognition. Coordination Chemistry Reviews. 205(1), 3-40.

Vashisht, D., K. Kaur., R. Jukaria., A. Vashisht., S. Sharma., S. Mehta., 2019. Colorimetric chemosensor based on coumarin skeleton for selective naked eye detection of cobalt (II) ion in near aqueous medium. Sensors and Actuators B: Chemical. 280, 219-226.

Wang, L., X. Gong., Q. Bing., G. Wang., 2018. A new oxadiazole-based dual-mode chemosensor: colorimetric detection of $\mathrm{Co}^{2+}$ and fluorometric detection of $\mathrm{Cu}^{2+}$ with high selectivity and sensitivity. Microchemical Journal. 142, 279-287.

*Correspondence: upulk@sjp.ac.lk

(C) University of Sri Jayewardenepura 
Wang, L., X. He., Y. Guo., J. Xu., S. Shao., 2011. Tris (indolyl) methene molecule as an anion receptor and colorimetric chemosensor: tunable selectivity and sensitivity for anions. Organic \& biomolecular chemistry. 9(3), 752-757.

Yamada, K., 2013. Cobalt: Its Role in Health and Disease. Metal ions in life sciences. 13, 295-320.

Yang, W., X. Chen., H. Su., W. Fang., Y. Zhang., 2015. The fluorescence regulation mechanism of the paramagnetic metal in a biological HNO sensor. Chemical communications. 51(47), 9616-9619.

Zahir, K. O., and H. Keshtkar., 1998. A Colorimetric Method for Trace Level Determination of Cobalt in Natural and Waste Water Samples. International Journal of Environmental Analytical Chemistry. 72(2), 151-162.

Zheng, X., W. Cheng., C. Ji., J. Zhang., M. Yin., 2020. Detection of metal ions in biological systems: A review. Reviews in Analytical Chemistry. 39(1), 231-246.

Zhu, S.-L., S.-J. Ji., K. Zhao., Y. Liu., 2008. Multicomponent reactions for the synthesis of new 3'indolyl substituted heterocycles under microwave irradiation. Tetrahedron Letters. 49(16), 25782582. 
Azees et al/ Vidyodaya Journal of Science Vol. 24 No. 02 (2021) 27-42 